Jpn. J. Phys. Fitness Sports Med. 2006, 55 Suppl. : S193 \$198

\title{
EFFECT OF DIETARY HEME-IRON INTAKES ON THE PREVENTION OF IRON-DEFICIENCY ANEMIA
}

\author{
KAORI HAYASHI $^{1)}$, NOBUYOSHI SHIOZAWA ${ }^{1)}$, YOSHIKO AKIYAMA ${ }^{1)}$, \\ YUKO MEKADA ${ }^{1)}$, HARUMI HIRATA ${ }^{2)}$, NORIKO TAKAHASHI ${ }^{3)}$, \\ OSAMU KASHIMURA ${ }^{4}$, ETSURO TANAKA ${ }^{2)}$, \\ TAKESHI SEKIGUCHI ${ }^{5}$ ) and YUKARI KAWANO ${ }^{2)}$
}

\begin{abstract}
Purpose : This study was undertaken to clarify the effect of heme-iron supplementation on the prevention of iron-deficiency anemia in male collegiate distance runners.

Methods : Forty-one male collegiate runners were divided into three groups, consisting of a heme-iron group (HI), a citrate-iron group (CI), and a non-iron group (NI). Iron tablets (hemeiron or citrate-iron) were administered at a dose of $7 \mathrm{mg}$ per day for two months. The blood components and nutritional intakes were estimated before and after the intervention.

Results : The nutritional intakes did not differ among the three groups. The red blood cell, hemoglobin, hematocrit, ferritin, Glutamic-Pyruvate Transferase and $\gamma$-Glutamyl Transpeptidase levels were unchanged throughout the experimental periods. After the intervention, the serum iron levels significantly decreased in the NI group but not in the iron-supplemented groups, while the reticulocytes counts increased among the three groups.

Conclusion : The small amount of heme-iron supplementation was thus found to have a preventive effect on iron deficiency anemia without causing any negative side affects.
\end{abstract}

(Jpn. J. Phys. Fitness Sports Med. 2006, 55 Suppl : S193 S198)

key word : runner, heme-iron, nutritional intake, liver function

\section{Introduction}

The decreased work capacity due to iron deficiency anemia in men has been well documented. Iron deficiency sometimes impairs the adaptive response to aerobic performance and it may impair the ability to sustain physical performance at $65 \sim 85 \%$ of maximal $\mathrm{O}_{2}$ utilization capacity $\left(\dot{\mathrm{V}} \mathrm{O}_{2} \mathrm{max}\right)$, i. e., endurance $^{1,2)}$. To reduce the impairment of aerobic performance induced by iron deficiency, many iron supplementation programs have been conducted for women using nonheme-iron. However, there have so far been few such reports on male runners. Telford et al. $^{3)}$ indicated that footstrike is the major contributor to haemolysis during running. If it is the main factor in the development of iron-deficiency anemia, then the prevention of footstrike haemolysis might be an extremely important concern for athletes, such as long distance runners.

It is well accepted that the bioavailability of dietary iron has a greater impact on the body iron status than does the ingested amount of iron or the composition of meals ; the difference in absorption between heme and nonheme-iron is therefore impor$\operatorname{tant}{ }^{4,5)}$. The effects of heme-iron supplementation on iron depletion without anemia have not yet been fully characterized in male runners.

In this study, we examined the effect of oral heme-iron supplementation for two months on the prevention of iron-deficiency anemia in male collegiate runners.

\footnotetext{
${ }^{1)}$ Graduate School of Agriculture, Tokyo University of Agriculture

${ }^{2)}$ Department of Nutritional Science, Tokyo University of Agriculture

${ }^{3)}$ Showagakuin

${ }^{4)}$ Faculty of international agriculture and food studies, Tokyo University of Agriculture

${ }^{5)}$ Ito Life Science Co., Ltd.
} 


\section{Methods}

Subjects : Forty-one collegiate male runners participated in this study for two months. Each participant gave their signed informed consent before the study began. The Tokyo University of Agriculture's Ethics Committee on Human Subjects approved this study.

Study design : Based on their basal body iron status, the subjects were assigned to three groups : including a non-supplement group (NI group, $n=13$ ), a heme-iron supplement group (HI group, $\mathrm{n}=13$ ), and a citrate iron supplement group (CI group, $\mathrm{n}=$ 15). All subjects completed an 8-week supplementation period. The heme- and citrate-iron tablets were kindly provided by Itoh Hamu Life Science Co., Japan; they contained $3.5 \mathrm{mg}$ elemental iron and were taken two times a day by each subject. The subjects were instructed to consume the tablets with their breakfast and dinner. They were also instructed to avoid the consumption of any other multivitamin and mineral supplements during the study period. All subjects recorded their tablet intake, consumption of medication, illness, gastrointestinal symptoms, physical activity, and musculoskeletal problems.

At baseline (Before) and at the end of the 8-wk intervention (After), all participants were instructed to refrain from strenuous activity for 24 hours and were asked to fast overnight before the day of blood sampling.

Dietary assessment : All subjects completed a semiquantitative food frequency questionnaire (FFQ) for the last 2-3 weeks using the EXCEL computer software program EIYOU KUN, consisting of a questionnaire based on the Standard Tables of Food Composition for Japanese ${ }^{6)}$.

Blood collection and measurements : Blood samples were taken at baseline (May) and at 8 wks after the start of the iron intervention (July). Blood samples were collected via a venepuncture of the antecubital vein in a sitting position on an empty stomach and the samples were drawn and kept in two evacuated tubes at the time the sample was obtained: one contained EDTA, while the other was empty. Hemoglobin $(\mathrm{Hb})$ and hematocrit $(\mathrm{Ht})$ were assayed in whole blood immediately after sampling. Hematological parameters, including red blood cell counts ( $\mathrm{RBC}), \mathrm{Hb}$, Ht, white blood cell counts (WBC), the mean corpuscular volume (MCV), themean corpuscular hemoglobin level (MCH), and the mean corpuscular hemoglobin concentration ( $\mathrm{MCHC}$ ), were estimated using a hematological Coulter CBC5 analyzer (Remed, Poland). The levels of reticulocytes, iron, ferritin, total iron binding capacity ( TIBC), erythropoietin (EPO), haptoglobin (hp), albumin (Alb), blood urea nit rogen $(B U N)$, uric acid (UA), glutamic oxaloacetic transaminase (GOT), glutamic pyruvic transaminase (GPT) and $\gamma$-glutamyl transpeptidase $(\gamma$-GTP) in serum were analyzed by Medical Laboratory Co. Ltd. (Kanagawa, Japan).

Statistical analysis : All data were expressed as the mean \pm standard deviation (SD). The statistical analysis was performed using the Statistical Package for Social Sciences (SPSS for Windows, version 12.0J, SPSS Inc., Japan). Values of $\mathrm{p}<0.05$ were considered to be statistically significant. The following statistical methods were used for comparisons between the groups.

To compare multiple independent groups (groups, time), two-way repeated measure analysis of variance (ANOVA) was performed as the initial step. If any differences were observed (main effect of group, interaction effect, $\mathrm{p}<0.05$ ), post hoc pairwise comparisons for the main effect on the time were by means of Friedman's nonparametric ANO. $\mathrm{VA}$. If a difference was observed in the main effect of the time, then the variables were analyzed by the Wilcoxon's signed-rank test. To compare these three independent groups, we checked the homogeneity of variance and tested for normal distribution in each group. If normal distributions were hypothesized in these groups, then a t-test was performed to compare the two means. If not, then the Mann-Whitney rank-test was performed. Statistical significance was accepted at a value of $\mathrm{p}<0.05$. 


\section{Results and Discussion}

No main effect of group or time and no group $\mathrm{x}$ time interaction effect on the running distances were observed. The mean running distances $( \pm \mathrm{SD})$ in the NI, HI, and CI groups were $647 \pm 197 \mathrm{~km}, 559 \pm 141$ $\mathrm{km}$, and $708 \pm 146 \mathrm{~km}$ in May and $648 \pm 197 \mathrm{~km}, 560$ $\pm 141 \mathrm{~km}$, and $708 \pm 145 \mathrm{~km}$ in July, respectively. There was no significant difference among the three groups; thus suggesting that the dietary iron supplementation did not affect the running distances.

No main effect of time or group and no time $x$ group interaction effect were observed for the nutritional intakes or for the food intakes except for white vegetables (time, $p<0.05$ ). The mean intakes of cereals in May and in July were $244 \pm 82 \mathrm{~g}$ and $233 \pm 70 \mathrm{~g}$, respectively ; potatoes $36.6 \pm 10.1 \mathrm{~g}$ and $25.9 \pm 7.1 \mathrm{~g}$; beans $86.3 \pm 17.9 \mathrm{~g}$ and $85.3 \pm 15.2 \mathrm{~g}$; fruits $66.6 \pm 15.8 \mathrm{~g}$ and $76.2 \pm 17.8 \mathrm{~g}$; total vegetables including green and white vegetables $269.6 \pm$ $108.8 \mathrm{~g}$ and $208.2 \pm 75.4 \mathrm{~g}$; beverages $250 \pm 184 \mathrm{~g}$ and $309 \pm 230 \mathrm{~g}$; milk and dairy products $271 \pm 79 \mathrm{~g}$ and $317 \pm 77 \mathrm{~g}$. Furthermore, there was no significant difference in the dietary iron intakes among the three groups during these experimental periods (mean dietary intake, $10.8 \mathrm{mg}$ ). Accordingly, the oral iron intakes were greater in both the $\mathrm{HI}$ and $\mathrm{CI}$ groups than in the NI group.

Although significant main effects of the time on $\operatorname{RBC}(\mathrm{p}<0.05), \operatorname{MCV}(\mathrm{p}<0.001), \operatorname{MCHC}(\mathrm{p}<0.001)$, and $\mathrm{MCH}(\mathrm{p}<0.001)$ were observed, no main effect of the group and no time $\mathrm{x}$ group interaction effect were observed. The levels of RBC $(\mathrm{p}<0.05)$ and $\operatorname{MCHC}(\mathrm{p}<0.001)$ were significantly lower in July than in May, and levels of MCV $(p<0.001)$ and $\mathrm{MCH}(\mathrm{p}<0.001)$ were significantly higher in July than in May. The mean $( \pm S D)$ serum iron levels in May and in July were $156 \pm 44 \mu \mathrm{g} / \mathrm{dl}$ and $109 \pm 22 \mu \mathrm{g} /$ $\mathrm{dl}$ in the NI group, $112 \pm 33 \mu \mathrm{g} / \mathrm{dl}$ and $89 \pm 43 \mu \mathrm{g} / \mathrm{dl}$ in the HI group, and $109 \pm 28 \mu \mathrm{g} / \mathrm{dl}$ and $99 \pm 333 \mu \mathrm{g} /$ $\mathrm{dl}$ in the CI group, respectively. The mean $( \pm \mathrm{SD})$ transferrin saturation levels in May and in July were $37.1 \pm 10.8 \%$ and $28.2 \pm 6.9 \%$ in the NI group,
$26.4 \pm 8.1 \%$ and $23.3 \pm 11.5 \%$ in the HI group, and $26.6 \pm 7.1 \%$ and $26.5 \pm 9.6 \%$ in the CI group, re spectively. A main effect of the group was observed in serum iron $(p<0.01)$ and transferrin saturation $(p<0.05)$. Main effects of time on $\operatorname{TIBC}(p<0.001)$, erythropoietin $(p<0.05)$, serum iron $(p<0.001)$, transferrin saturation $(\mathrm{p}<0.05)$, and reticulocytes $(p<0.001)$ were observed (Fig. 1). The mean erythropoietin concentrations of all three groups were significantly higher in July than in May, while the serum iron levels were significantly lower in July than in May, especially in the NI group. The mean transferrin saturation levels in the NI group significantly decreased in July, but not in either the $\mathrm{HI}$ or the CI groups. However, no time $\mathrm{x}$ group interaction effects were observed for any hematological parameters.

No main effect of the group, the main effect of the time and the group $\mathrm{x}$ time interaction effect on UA, GPT, and $\gamma$-GTP was observed (Table 1 ). These results suggested that dietary heme- or citrate-iron supplementation for 8 weeks at a level of $7 \mathrm{mg}$ per day did not induce any negative side effects in the bodily functions. It seems likely that dietary iron supplementation under our experimental conditions does not have any harmful effect on the liver function, and therefore the consumption of $7 \mathrm{mg}$ of iron per day for 2 months appears to be safe.

Hinton et al. ${ }^{7)}$ investigated the effect of iron supplementation on the work rate in iron-depleted nonanemic women during a $15-\mathrm{km}$ time trial and reported that iron supplementation (100 mg of ferrous sulfate) increased the serum ferritin level and decreased the level of transferrin receptors, and the decrease in the $15-\mathrm{km}$ time was also greater in the supplemented group. These results in the hematological changes corresponded well with our ferritin levels (data not shown), thus suggesting that dietary iron supplementation might improve the running time.

Although many reports involve $100 \mathrm{mg}$ iron supplementation, health problems resulting from an excessive intake of iron might occur at this high dose 
A. $\operatorname{Serum} \operatorname{iron}(\mu \mathrm{g} / \mathrm{dl})$

\section{1)Control (NI)}

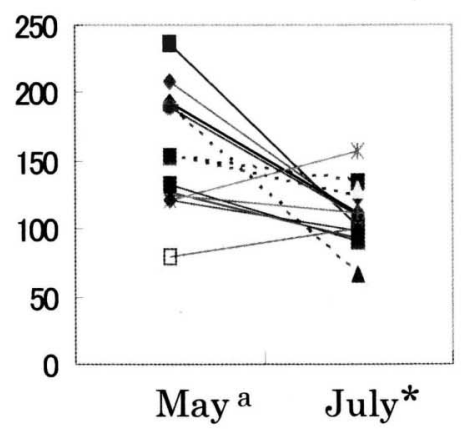

B. Transferrin saturation (\%)

\section{1) Control (NI)}

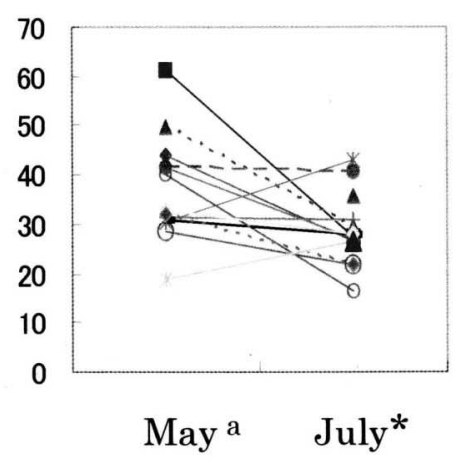

C. Reticulocytes (\%o)

\section{1) Control (NI)}

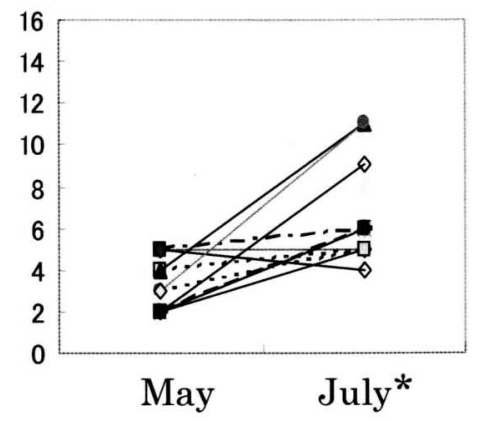

2) Heme $\digamma \mathrm{e}(\mathrm{HI})$

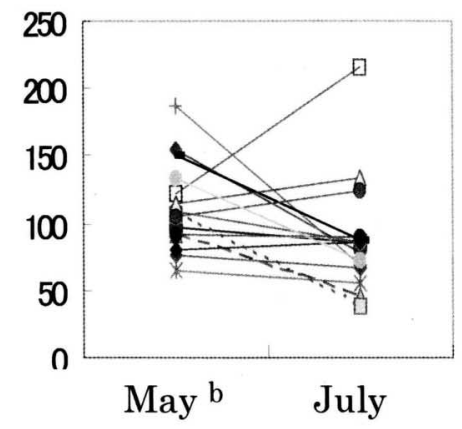

2) Heme- $\mathrm{Fe}(\mathrm{HI})$

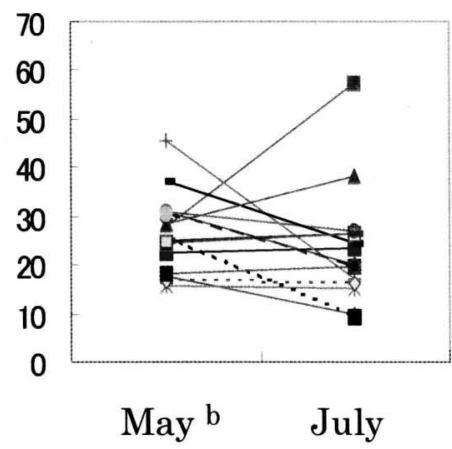

2) Heme $F e(H I)$

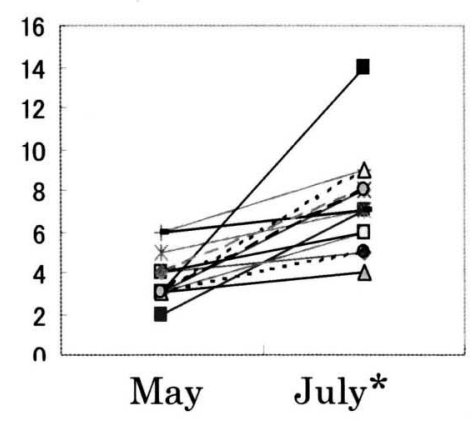

3)Citrate $F e(\mathrm{CI})$

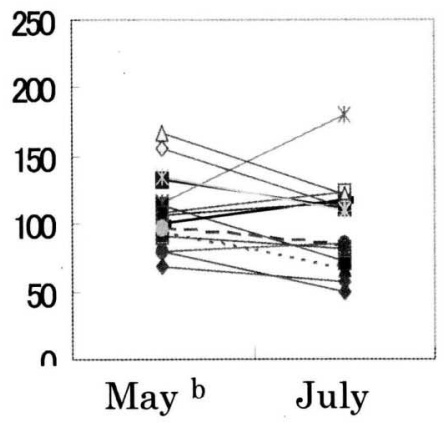

3) Citrate $F e(\mathrm{CI})$

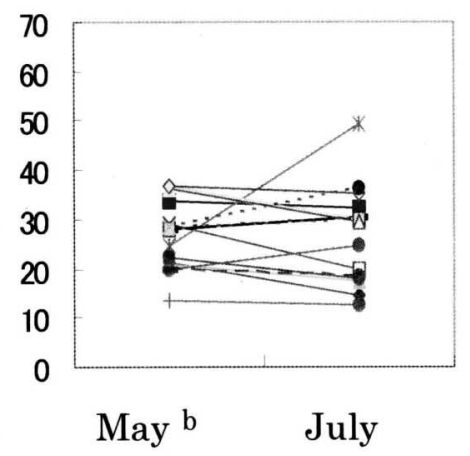

Fig 1. The effect of dietary iron supplementation on the body iron status.

A : The serum iron concentration ( $\mu \mathrm{g} / \mathrm{dl}), \mathrm{B}$ : Transferrin saturation (\%), C : Reticulocyte counts (\%o). Abbreviations : $a-b$ : significantly different from each other $(p<0.05) .{ }^{*}$ : significantly difference between the values obtained in May and in July $(\mathrm{p}<0.05)$.

level. In our study, subjects consumed an additional $7 \mathrm{mg}$ iron as either heme- or citrate-iron. If the prevention of iron deficiency anemia can be achieved with both small and larger amounts of dietary iron supplementation, then the small amount would thus be preferred because of the lower potential for adverse effects, especially regarding long-term supplementation.

Further studies are needed to clarify the optimal dosage of dietary iron supplementation for the prevention of iron deficiency anemia. 
Table 1. Comparison of the biochemical analysis data.

\begin{tabular}{|c|c|c|c|c|c|c|}
\hline \multicolumn{2}{|c|}{ Intervention } & \multirow[t]{2}{*}{ May } & \multirow[t]{2}{*}{ July } & \multicolumn{3}{|c|}{ ANOVA } \\
\hline & Grol & & & Group & Int & $\begin{array}{l}\text { Group } \\
\times \quad \text { In } \\
\end{array}$ \\
\hline$\overline{T P}$ & $\begin{array}{l}\mathrm{NI} \\
\mathrm{HI} \\
\mathrm{CI} \\
\text { Total }\end{array}$ & $\begin{array}{l}7.68 \pm 0.37 \\
7.54 \pm 0.26 \\
7.50 \pm 0.28 \\
7.57 \pm 0.30\end{array}$ & $\begin{array}{l}7.77 \pm 0.31 \mathrm{a} \\
7.46 \pm 0.37 \mathrm{c} \\
7.47 \pm 0.40 \mathrm{~b} \\
7.56 \pm 0.38\end{array}$ & 0.048 & 0.906 & 0.486 \\
\hline$\overline{\mathrm{ALB}}$ & $\begin{array}{l}\mathrm{NI} \\
\mathrm{HI} \\
\mathrm{CI} \\
\text { Total }\end{array}$ & $\begin{array}{l}4.73 \pm 0.20 \\
4.71 \pm 0.22 \\
4.68 \pm 0.14 \\
4.71 \pm 0.18\end{array}$ & $\begin{array}{l}5.06 \pm 0.26 a, * * \\
4.89 \pm 0.25 * \\
4.88 \pm 0.24 b, * * \\
4.94 \pm 0.26\end{array}$ & 0.214 & 0.000 & 0.237 \\
\hline$\overline{A / G}$ & $\begin{array}{l}\mathrm{NI} \\
\mathrm{HI} \\
\mathrm{CI} \\
\text { Total }\end{array}$ & $\begin{array}{l}1.62 \pm 0.20 \\
1.68 \pm 0.20 \\
1.67 \pm 0.15 \\
1.66 \pm 0.18\end{array}$ & $\begin{array}{l}1.91 \pm 0.26 * * \\
1.93 \pm 0.30 * * \\
1.91 \pm 0.22 * * \\
1.92 \pm 0.25\end{array}$ & 0.855 & 0.000 & 0.738 \\
\hline BUN & $\begin{array}{l}\mathrm{NI} \\
\mathrm{HI} \\
\mathrm{CI} \\
\text { Total }\end{array}$ & $\begin{array}{l}17.2 \pm 4.3 a \\
19.8 \pm 5.0 \\
20.7 \pm 3.7 b \\
19.4 \pm 4.5 \\
\end{array}$ & $\begin{array}{l}15.2 \pm 5.2 \\
17.9 \pm 3.3 \\
17.4 \pm 4.7 * \\
16.9 \pm 4.5 \\
\end{array}$ & 0.126 & 0.000 & 0.540 \\
\hline$\overline{U A}$ & $\begin{array}{l}\mathrm{NI} \\
\mathrm{HI} \\
\mathrm{CI} \\
\text { Total }\end{array}$ & $\begin{array}{l}5.82 \pm 0.95 \\
5.45 \pm 0.82 \\
5.47 \pm 1.13 \\
5.57 \pm 0.96 \\
\end{array}$ & $\begin{array}{l}5.92 \pm 0.76 \\
5.74 \pm 1.21 \\
5.45 \pm 0.97 \\
5.69 \pm 1.00 \\
\end{array}$ & 0.502 & 0.279 & 0.538 \\
\hline GOT & $\begin{array}{l}\mathrm{NI} \\
\mathrm{HI} \\
\mathrm{CI} \\
\text { Total }\end{array}$ & $\begin{array}{l}28.3 \pm 5.1 \\
30.2 \pm 13.9 \\
27.9 \pm 4.5 \\
28.8 \pm \quad 8.9\end{array}$ & $\begin{array}{l}23.3 \pm 5.3 * \\
22.1 \pm 6.6 * * \\
22.2 \pm 5.1 * \\
22.5 \pm \quad 5.6\end{array}$ & 0.889 & 0.000 & 0.597 \\
\hline$\overline{\mathrm{GPT}}$ & $\begin{array}{l}\mathrm{NI} \\
\mathrm{HI} \\
\mathrm{CI} \\
\text { Total }\end{array}$ & $\begin{array}{l}21.8 \pm 4.5 \\
21.7 \pm \quad 7.9 \\
21.7 \pm \quad 5.7 \\
217 \pm \quad 6.2\end{array}$ & $\begin{array}{l}21.8 \pm \quad 6.6 \\
19.5 \pm \quad 8.8 \\
20.5 \pm \quad 6.2 \\
20.5 \pm \quad 72 \\
\end{array}$ & 0.856 & 0.302 & 0.689 \\
\hline$\gamma-\mathrm{GTP}$ & $\begin{array}{l}\mathrm{NI} \\
\mathrm{HI} \\
\mathrm{CI} \\
\text { Total }\end{array}$ & $\begin{array}{l}12.9 \pm \quad 3.1 \\
10.9 \pm \quad 2.8 \\
14.7 \pm \quad 6.7 \\
12.8 \pm \quad 4.8 \\
\end{array}$ & $\begin{array}{l}13.8 \pm 3.5 \\
11.3 \pm 1.8 \mathrm{a} \\
14.0 \pm 3.6 \mathrm{~b} \\
13.0 \pm \quad 3.2 \\
\end{array}$ & 0.052 & 0.620 & 0.391 \\
\hline
\end{tabular}

Means are significantly different from the May levels ; ${ }^{*} \mathrm{p}<0.05,{ }^{*}{ }_{\mathrm{p}}<0.01$.

Different letters indicate a statistically significant difference. all data are expressed as the mean \pm SD. NI : Control, HI : Heme-iron group, CI : Citrate-iron group.

\section{Acknowledgements}

This study was supported by a Grant-in-Aid for Scientific Research C (No. 16500521) from the Japan Society for the Promotion of Science (JSPS) and was supported by Itoh Life Science in 2004.

\section{References}

1) Davies, K., Donovan, M., Refino, C., Brooks, G., Packer, L., \& Dallman, P. Distinguishing effects of anemia and muscle iron deficiency on exercise bioenergetics in the rat. Am. J. Physiol. Endocrinol. Metab.,(1984),
246, E535-E543.

2) Willis, W., Brooks, G., Hendeerson, S., \& Dallman, P. Effects of iron deficiency and training on mitochondrial enzymes in skeletal muscle. J. Appl. Physiol., (1987), 62, 2442-2446.

3) Telford, R. D., Sly, G. J., Hahn, A. G., Cunningham, R. B., Bryant, C., \& Smith, J.A. Footstrike is the major cause of hemolysis during running. J. Appl. Physiol., (2003), 94, 38-42.

4) Raffin, S. B., Woo, C. H., Roost, K. T., Price, D. C., \& Schmid, R. Intestinal absorption of hemoglobin heme iron cleavage by mucosal heme oxygenase. J. Clin. Invest.,(1974), 54, 1344-1352.

5) Hallberg, L., BjØrn-Rasmussen, E., Howard, L., \& 
Rossander, L. Dietary heme iron absorption. A discussion of possible mechanisms for the absorptionpromoting effect of meat and for the regulation of iron absorption. Scand. J. Gastroent.,(1979), 14, 769-779.

6) Takahashi K. Food frequency questionnaire based on food groups for estimating individual nutrient intake.
Jpn. J. Nutr. Diet.,(2003), 61, 161-169.

7) Hinton, P. S., Giordano, C., Brownlie, T., \& Haas, J. D. Iron supplementation improves endurance after training in iron-depleted nonanemic women. J. Appl. Physiol.,(2000), 88, 1103-1111. 